\title{
Comparative Study of the Attitudes of Rural and Urban Punjabi Society towards Caste Stereotypes in Punjabi Language \\ Mehmood UI Hassan
}

Lecturer the University of Lahore, Pakpattan Campus, Pakistan

Email:mehmood.uol@gmail.com

Muhammad Qasim Ali

Ph.D. (Scholar) Bahauddin Zakariya University, Multan, Pakistan

Email: qasimvr@yahoo.com

Abdul Hameed Zahid

Headmaster Govt. High School Douna Sistrict Muzafargarh, Pakistan Email: hameedji123@gmail.com

Saeed Ahmad

Ph.D Scholar Department of English The Islamia University Bahwalpur,Pakistan Email: saeed.dsd@gmail.com

\section{Muhammad Zafar Iqbal}

Ph.D. (Scholar) International Islamic University, Islamabad, Pakistan Email: zafar.phdedu57@iiu.edu.pk

Zafar Masaud

Ph.D. (Scholar), Preston University, Islamabad, Pakistan Email: zafarmasaud@gmail.com

\section{Doi:10.5901/mjss.2015.v6n1s1p620}

\section{Abstract}

This study compares attitudes of rural/urban population of Punjab (Pakistan) towards caste-stereotypes in Punjabi language. The data were collected from District Vehari of southern Punjab including its two adjacent sub-divisions Burewla and Mailsi through questionnaire and interviews; and analyzed using SPSS. The results reveal that there is considerable difference among the attitudes of urban/rural population regarding beliefs and foundations of the caste-stereotypes and their impacts on social life. Besides, people living in rural areas are more prone to using caste-stereotypes than their urban counterparts. Similar trend is observed in the effect of caste-stereotypes on their social relations.

Keywords: Attitude, Punjabi Society, Caste-Stereotypes, Punjabi Language; Pakistan

\section{Introduction}

Socio linguistics is a very vast subject that studies the social aspects of language. And Language is the geographical, social and cultural phenomenon and has deep rooted relation with society. Mehmood et al (2011) describe that language is not a static phenomenon and contains a lot of variations and these variations are on the basis of age, sex, power, status, ethnicity, gender and caste. We see in our general life that different age groups speak differently with different selection of vocabulary in social life.

Mitchell (2005) reported that when we speak, we not only communicate with others but also exhibit in an indirect way which territory we belong to by showing our identity where do we belong to?. Rahman (1997) says that a person 
might-define himself or herself in terms of sex (male or female) family role (son, daughter, wife) occupation (weaver or Jolaha) tribe or clan (Mughal, Pathan, Arain, Sheikh) economic class. Such labeling is part of self perception and also perception by others. Ethnicity is the socially constructed category which is not based on any objectively measurable criteria (Fought, 2006). Mehmood et al (2011) are of the view that ethnic membership is different from the kinship or blood relationship group and in literature, dress, religion, color and music are repeatedly given pertaining to a particular group of some country and we can identify them by looking at them on the basis of our conception. Rehman (2003) states that, just two years after the establishment of the newly born state (Pakistan) faced severe ethnic and racial problems regarding the official language. This was a linguistic issue that resulted in the partition of Pakistan in 1971.

Apart from the intercultural linguistic ethnic issues in Pakistan one more important linguistic issue is regarding caste stereotypes in Punjabi language. In Punjab, there exist a large number of groups each one of which represents its own specific linguistic identity and possesses its own status as a different class. As a result numerous social issues are rising out of biased and prejudiced society and stereotypes associated with different castes are playing for front role. People of Punjab belong to racial groups or communities who have subjective belief in their common descent. Each caste is associated with particular stereotypes in Punjabi language to be classed as other.

Sial (2008) is of the view that caste-stereotypes in Punjabi language are also very common social phenomenon which has been deeply rooted in race and ethnicity in the Punjabi society even countless years before the establishment of Pakistan. Caste-stereotypes are an instrument in a language used to identify others as different class and this Identification through language is a salient feature in stereotypes communication.

In Punjabi society, in-groups and out-groups notions are very common. It is because touchable and untouchable and the superior and the inferior social status were prevalent in the Indian society for over centuries. People have perceptions in mind to keep themselves as different class. These concepts are based on cognitive characteristics pertaining to many castes and represent social groups as if that they can be called stereotypes because they are associated with caste that is why they are named as caste-stereotypes. In Punjab where such a large variety of castes exists, stereotypes communication in Punjabi language in social gathering like Punchayat (public meeting) and general meetings, are very common.

The present study was conducted to investigate into caste stereotypes in Punjabi language pertaining to various castes in Punjabi society. Stereotypes associated with upper class castes like Kamboh, Arain, Baloch, Jatt, Gujjar, Dogar, Rangarh and Sheikh describe the particular characteristics of these socially dominated castes. Due to the nature of their professions there developed in them such habitual characteristics which caricature them as humiliated and disgraceful in the society. These particular classes are called Julaha (Weavers), Nai (Barbars), Mochi (shoe makers) and Telli (Oil men).

Caste-stereotypes associated with them and the higher social groups are the product of social experiences of the Punjabi society. That is why they can also be called social phenomenon. Besides, the higher social groups have also their own perceptions (stereotypes) about their castes or clans. These stereotypical perceptions are based on their regular and habitual recognizable characteristics.

The purpose of this study was to highlight the comparative attitudes towards caste stereotypes in Punjabi language between the rural and urban populations in terms of their beliefs in caste-stereotypes, foundation of caste- stereotypes and their impacts on their social lives.

\section{Literature Review}

Language is a social phenomenon (Hudson, 1987). Linguists have put forward a number of, theories, themes and ideas to describe what a language is? Ronald (2006) states when two or more people come to communicate with each other in speech, we name it the system of communication that they use a code. In most cases that code might be something we may also want to name it a language.

Hudson (1987) discusses that people utilize language to find themselves in multi-dimensional social space. On speaker's side, this is the way of imparting information about himself, about the kind of person he is or would like to be and his status in the society where he is existing and as a result the hearer may reach the consequences about what characteristics and status a speaker has.

Rehman (2003) discussed the historical perspective of ethnicity as result of which language movements started after and before the partition of Bengal in 1971. He said that Pakistan also came into being because Muslims wanted Urdu to adopt as their official language and on the contrary Hindus wanted Hindi as their own recognized language as well. The Ethno-nationalists gave birth to secularism and evoked language and culture etc to support their cause. They had a fear of being deprived of jobs, of being powerless and of remaining underdeveloped. In 1960, Punjabi, Pakhtun, 
Sindhi, Balochi and Bengali were declared five indigenous nationalities and in 1980 Muhajirs also began to call themselves as separate identity. All these emerging thoughts in the minds of different social groups have been jeopardizing the negative ideologies.

Referring to the Indian situation, Sinha (1967) described that the belief and practice of caste are very common not only among the Hindus, but also among the Muslims. Pakistani society, an ex-part of India, has vivid stratifications of economic classes, regions, the rural and urban domains, tribal, feudal, and capitalist social formations. So Ethnic groups having different social thinking and picture in their minds for other ethnic groups give rise to behavior stereotypes.

Anthony et al (2007) explores that culturally shared beliefs, values, and practices are sine qua non of social life; it is a truism to say that society cannot exist without culture. Yet, shared beliefs and ideas can be at the heart of many social issues and problems as well; whether it is inequality, prejudice, intergroup conflict, terrorism, or other social issues or problem.

Ifegbesan (2010) attempted to find out that educational system not only generates traditional gender roles but also attitudes toward gender stereotypes. Most of the teachers possess gender-stereotypes and practice these stereotypes in schools. They hold or perpetuate biased perceptions of males and females but deny this fact. The results of this research show a significant difference between the gender stereotype belief, attitudes and practices of males and females teachers.

This research recommends that our teachers must learn to blot out gender bias in their student-teachers interactions both within and outside the classroom. Seminars and workshops should be conducted for teachers who are in-service administrators and parents to get them awareness to gender issues and their consequences on the learners. When stakeholders get acquaintance of their gender-biased behaviors, practices and apply strategies to counter bias, are better able to propagate gender equity in their classrooms and society.

Calvert et al (2003) made an experimental research on Gender Stereotyping in Children's reports about educational and informational Television Programs. Children from the 2nd to 6th grade asked to provide reports about their favorite educational and informational television programs, and then reports were examined for the presence of gender stereotypes. The reports presented by the children contained more male than female characters, more male than female pronouns, and more masculine than feminine behaviors. It was observed that the effects were most pronounced for boys. Over time, preadolescent girls were seen showing greater preference for educational programs that demonstrated female lead characters, and the girls were also seen using more feminine pronouns, behaviors, and exposed a greater range of feelings in their writings about their favorite programs. Girls and boys, however, were more possibly to report masculine behaviors for male and female characters. Moreover, gender-stereotyping effects were blotted out for boys who chose a favorite program featuring an adventurous female lead character.

Talbot (2003) researched on stereotypes representation of women and found out differences. Behavior of women was complaining, as they represented themselves as either bitching or nagging while males behaved wisely and gave natural explanation. This research gives the possibility that wide spreading perception of communication skills as feminine will paste the lasting impacts on one of the "good stereotypes" considered earlier. She discovered that sometimes it was seen women's talk was no longer being judged against an ideal of female silence. However, it was not dead sure that keeping aloft the nurturing, supportive and soft verbal behavior which is distinctive characteristic of the female interactional style as superior "communication" in fact commits anything to disturb hegemonic male superiority and female subordination.

Rehman (1997) worked on ethnic based Punjabi language movement which has been deliberately handled and lead by the leaders for instrumental, rational, goal-seeking reasons: just for the provocation of a pressure group to achieve greater power, goods, or services from the state, or to redress a situation of internal colonialism that was being considered as unfair and unjust. In the Punjabi movement, however, extra rational sentiment is the major motivation behind. It is the cherished element for self-respect, for the acceptance of one's identity without culture-shame, and for psychological fulfillment without being taken up language and the behavior of another culture. He further notified that language is an identity marker that gives birth to a community, in the modern world when supra local solidarities and large communities could be imagined in the age of printing and the nation. He observed that language movements are part of ethnic assertions which meant to counter perceived domination and injustice, linguistic policies alone are not going to be helpful. He was of the view that a language will be incessantly resisted even by its own speakers-as mother-tongue schooling had been in South Africa, the NWFP and Balochistan if it is not used in the domains of power and commerce or if it is otherwise disliked socially.

In order to establish a secure country where ethnicity is no longer a Damocles' sword, a truly federal (or even confederal) political order may be part and parcel. This study gives suggestion that Pakistan should have five national languages while Urdu for interprovincial communication and English for international purposes. More importantly, it 
suggests that the provinces, which may be reordered along ethnic and linguistic lines, should be genuinely brought in power. Such empowerment shall possibly be a step toward postmodernist vision (Rahman, 2001) of a less conflict-prone society based upon decentralization. No federating unit would select to opt out of a system in which it is responsible for its own fate and is no longer under ruled by the central government. He said that under these conditions, ethnicity can be a blessing and augment the Pakistani state's rich and variant culture.

Zhang (2009) put forth an analysis based on one factor called stereotypes. He threw light on two aspects of stereotypes: inaccurate and accurate stereotypes. He described that in intercultural research, the influence of stereotypes on people's behaviors in communication is a very important issue to take into account. He aims to illustrate stereotypes from the aspects of their social and psychological perspectives, great impacts on people's communication, the problems they may cause, and some solutions. He described accurate stereotypes and inaccurate stereotypes. Accurate stereotypes support us to give cultural-level pre information about the strangers' behavior and inaccurate stereotypes mislead us to the understanding of others. He also discussed the problems caused by the stereotypes and their solutions.

It was reported in the study of Micah et al (2000) that at the extreme, social stereotypes can be learned either from direct contact with individual target group members or from communications about the target group received from others. These two forms of stereotype acquisition have consequences for the nature and content of the stereotype that is formed (Park \& Hastie, 1987). The present studies examine these consequences using, in the first study, a rumor transmission design and, in the second, group discussions. The first study demonstrates that stereotypes that are received from others are more extreme, contain less variability information, and have higher social consensus than stereotypes learned from contact with individual target group members. The second study demonstrates that stereotypes that are communicated and learned through informal group discussions manifest the same properties. The researcher argues that stereotypes are fundamentally altered through social communication and these effects are in part responsible for the biases that stereotypes induce.

Anesbury \& tiggeymann (2000) attempted to negative stereotyping by teaching about the uncontrollability of obesity. Over all the study has an important applied implication. The results show that the parents and the teachers can successfully use messages about uncontrollability of obesity to change children beliefs that obesity is controllable. These messages could be incorporated in health and nutrition courses in schools to improve children understanding of the factors involved in determining weight. Information of this kind would be especially useful for those children who strongly believe that obesity is controlled by the individual and negatively stereotype children based on that belief. Secondly it is imperative for parents and the teachers to address the problem of negative stereotyping of obesity in children, a problem that often goes unrecognized. The schools should be encouraged to incorporate programs which attack negative stereotyping as this study has attempted. This would certainly benefit the overweight and obese children whose self concept and psychological well-being is at risk.

All above studies were conducted on manipulation and learning about stereotypes and stereotyping obesity in children. Caste stereotypes study in Punjabi language was new dimension in stereotypes communication that remained untouched. This study is different from the rest as this study gives insight into understanding the nature of people belonging to various social groups within the same Punjabi society where one stereotype associated with caste looms the whole picture large about activities, habits and the attitudes of the opposite caste. Unlike gender stereotyping and many others, caste stereotypes are the production of biased and prejudiced social set up which are affecting the social life of the people. Studying these Caste stereotypes in Punjabi language through "comparison among the Rural and the Urban population" is a new dimension.

This was a sociolinguistic research and it fills the gap by exploring caste stereotypes dimension in Punjabi language which was a missing aspect of this area.

\section{Objectives of the Study}

For conducting the present study following objectives were set to work on:

1. To compare the attitudes of Rural and the Urban population regarding their beliefs towards caste-stereotypes in Punjabi language.

2. To find out comparison of the perceptions of Rural and the Urban population towards the foundations of Castestereotypes in Punjabi language.

3. To explore comparison of the perceptions of Rural and the Urban population towards the impacts of castestereotypes on the social relations in Punjabi language. 


\section{Research Methodology}

Fundamentally it was a non-experimental research which included survey through questionnaire comprising 5-point Likert Scale. The research was conducted in the district Vehari of southern Punjab, Pakistan. The questionnaire was developed on the basis of. Caste-stereotypes collected through interviews form the Rural and the Urban population of Punjab. This was survey research. So data were collected through survey by distributing the questionnaires to the people conveniently. It was qualitative as well as quantitative research. These approaches were adopted because quantitative and qualitative results part and parcel to seen. Quantitative data were analyzed using SPSS. It was because quantitative results for the comparison between the Rural and the Urban were to be seen on various indicators given in the questionnaire. Then the quantitative results were discussed qualitatively on the basis views given in various studies conducted and the views of the rural and the urban population in Punjab.

Table 1: Peoples' Beliefs of Caste Stereotypes

\begin{tabular}{c|ccccc}
\hline Variable & Area & Mean & SD & t & P \\
\hline Belief in caste & Rural & 12.90 & 2.88 & \multirow{2}{*}{2.34} & \multirow{2}{*}{$0.021^{*}$} \\
Stereotypes & Urban & 12.38 & 3.97 & & \\
\hline$\left(\mathrm{N}=60, \mathrm{df}=118,{ }^{\star \star \star} \mathrm{p}<0.01\right)$ & & & & &
\end{tabular}

Table 1 shows comparative results of the attitudes of Urban and Rural population towards beliefs in the caste stereotypes in Punjabi language. It is clear from the mean scores and standard deviation that people living in the Rural areas have stronger attitudes towards belief in caste-stereotypes. Through interviews it was further explored that people living in Punjab, these stereotypes help them providing pre-understanding of the other castes or social groups belonging to Punjabi society. They believe that these stereotypes have bequeathed to them and become the part of their communication.

Table 2: Peoples' Attitudes towards the Foundation of Castes Stereotypes

\begin{tabular}{c|ccccc}
\hline Variable & Area & Mean & SD & $t$ & P \\
\hline Foundation of & Rural & 12.68 & 3.30 & \multirow{2}{*}{3.50} & \multirow{2}{*}{$0.000^{\star * \star}$} \\
caste stereotypes & Urban & 10.47 & 3.64 & & \\
\hline
\end{tabular}

$\left(\mathrm{N}=60, \mathrm{df}=118,{ }^{\star \star \star} \mathrm{p}<0.01\right)$

Table 2 shows the comparison of attitudes of the rural and the urban population towards the foundation of castesstereotypes used in Punjabi language. We can see from the mean scores and standard deviation that rural society is comparatively more prone towards foundation of caste-stereotypes in Punjabi language than the urban society. Somehow, both urban and the rural societies know very well that foundation of caste-stereotypes is based on collective wisdom, illiteracy, discriminated based Indian system of castes, prejudice in people and feudalism in rural areas of Punjab.

Table 3: Impacts of Caste Stereotypes on the Social Relations of the People

\begin{tabular}{c|ccccc}
\hline Variable & Area & Mean & SD & T & P \\
\hline Caste stereotypes & Rural & 12.65 & 3.34 & \multirow{2}{*}{2.11} & \multirow{2}{*}{0.045} \\
\& social relations & Urban & 12.73 & 3.25 & & \\
\hline
\end{tabular}

$\left(N=60, d f=118,{ }^{* * *} p<0.01\right)$

Table 3 reveals the comparison of the attitudes of the rural and the urban societies towards the impacts of castestereotypes on the social relations of the people in Punjab. We can see from the mean score and standard deviation that there is very minute difference in the attitudes between the rural and the urban societies towards caste-stereotypes in Punjabi language in terms of their impacts on the social relations of the people. The results confirm that people in rural and urban areas equally rated the negative impacts of the caste-stereotypes in Punjabi society. 


\section{Discussion}

The comparative details regarding the attitudinal beliefs of the rural and the urban society towards caste-stereotypes in Punjabi language, gives us insight into complex structure of communication of the people in Punjab (Pakistan). People living in rural areas have stronger beliefs towards caste stereotypes. There are various reasons for this. First, in rural life, many of the traditional and conventional conservative principles are being followed without knowing their negative impacts on their social lives. They follow all such conventions and traditions just because their forefathers and ancestors have been doing for a long time before them and they want to keep them up now. The stereotypical representations of the castes in Punjab are their forefathers' self created intellectual and cognitive images to which they believe to be accurate. This rating is comparatively less in urban areas. The $2^{\text {nd }}$ reason is the social constraint. As this study confirms the research conducted by Ibbetson (1916) who asserts that there were tribal, occupational and agricultural based social constraints due to which people were prejudiced and biased against one another.

In addition to this, specific class of people urges to play valuable role in the social fiber due to the feudal system existing in Punjab. This authoritative role is another cause to the origination of caste stereotype. Moreover, Indian caste system has great deal of discrimination with reference to higher and the lower castes (untouchables etc). This system also caused to develop such stereotypes in Punjabi language. As a result such discriminated caste system gave birth to biased and prejudiced society reinforcing the development of such pictures in the heads of the people in Punjab which became the basis to these stereotypes still existing in the society.

Thirdly, comparison reveals that the impacts of the caste stereotypes in Punjabi language on rural and the urban population vary. As people in the urban areas have less concerned attitudes towards such cognitive characteristics due to higher academic back grounds, inter-caste marriages, and busy routine life. As a result, caste-stereotypes in social communication of the urban people having less impacts on their social life as compared to people in rural areas. This study also confirms the research conducted by Zhang (2009). He threw light on two aspects of stereotypes: inaccurate and accurate stereotypes. He described accurate stereotypes and inaccurate stereotypes. Accurate stereotypes support us to give cultural-level pre information about the strangers' behavior and inaccurate stereotypes mislead us to the understanding of others.

The negative attitude of the people in rural areas does not allow them to commit intermarriages and to mix up with other people with different castes. Such conservative practices are more prevalent in rural areas than urban. Ibbetson's (1916) study also supports the same that due to the classifications based on professions, agriculture etc people belonging to various social groups do not intermarry and are not hand in glove with each other behind all that there was prejudice among the people by dint of the caste stereotypes used in Punjabi language.

\section{Conclusion}

Elder (2011) states that the castes are born up of marrying within one's own lineages which forms one's ultimate base of social support. Caste mechanism gives such an environment that can be conducive in the old age. Like Zhang's study of stereotypes communication: inaccurate and accurate stereotypes, the impacts of caste-stereotypes on people's behavior and social relation, are a very important issue to take into account. Accurate caste-stereotypes are also in use and such stereotypes support the rural as well as the urban people to give cultural-level pre-information about the strangers' behavior and according to the attitudes of the urban people, inaccurate caste-stereotypes in Punjabi people mislead them to the understanding of others that is why their attitudes towards caste stereotypes is less serious as compare to people dwelling in rural territories who think and believe in the other way round.

\section{References}

Anesbury, T \& Tiggeymann, M. (2000). An attempt to reduce negative stereotyping of obesity in children by changing controllability beliefs. Health Education Research Vol.5 (2) pp 145-152.

Calvert, S. L. Kotler J. A. Zehnder, S. M. \& Shockey, E. M. (2003). Gender Stereotyping in Children's Reports about Educational and Informational Television Programs. Media Psychology 5, 139-162.

Cohen, L \& L. Manion. (2005). Research Methods in Education. London: Routledge.

Elder, J. (2011). India's Caste System available at http://www .dalitusa .org/es.html (accessed on 30. 02. 2014).

Hudson, R.A. (1987). Sociolinguistics. London: Cambridge University Press.

Ifegbesan, A. (2010). Gender Stereotypes Beliefs \& Practices in the class room: the Nigerian Post primary School teachers' Global Journal of Human Social science.Vol.10, 29-36.

Khan, A. (2009). A Temporal view of socio-political changes in Punjab: A Research Journal of South Asian Studies. Vol. (24)2. 
Hassan, M. Kazim, S. S, Sarwar, M \& Alam, M. (2011). The Sociolinguistic Study of Caste Stereotypes in the Language of Punjabi Society. African Journal of Business Management. Academic Journals. Vol. 5(11), pp. 4485-4489.

Micah, S. Thompson, Charles M. Judd \& Park, B. (2000). The Consequences of Communicating Social Stereotypes. Journal of Experimental Social Psychology. Vol. 36( 6) P. 567-599.

Michell, C. (2005). Behind the Ethnic marker: Religion and Social Identification in Northern Ireland. Sociology of Religion.66: $13-21$.

Rehman, T. (1997). Language and Ethnicity. Asian Surv. 37(9): 833-839.

Rahman, T. (2001). Language and Ethnicity in Pakistan. Asian Survey. 37(9):833-839.

Rehman, T. (2003). Language and Politics in Pakistan. Oxford University Press.

Rolling, J. H. (2010). Stereotypes: Encyclopedia of Identities. Retrieves from Academia.edu on 23, June, 2014.

Ronald,W. (2006). An Introduction to Sociolinguistics. $5^{\text {th }}$ ed. Blackwell Publishing.

Sial, S. (2008). Exloring the Mindset of the British Community: the Socio-cultural and Religious context. Pakistan Institute for Peace Studies.

Sinha, G. S, Sinha, R. C. (1967). Exploration in Caste Stereotypes. Social Forces.46 (1):42.

Talbot, M. (2003). Gender stereotypes: reproduction and challenges. Reprinted in UK. Blackwell Publishing Holmes, j \& Meyer hoff, M. Ed. The Hand book of Language and Gender :UK.Blackwell Publishing.

Zhang, S. \& Deng, D. (2009). Stereotypes Communication. Int. Educ. Stud., 2(4): 25-27. 